\title{
A Global Study of a Contactless Energy Transfer System: Analytical Design, Virtual Prototyping, and Experimental Validation
}

\author{
Jean-Romain Sibué, Gatien Kwimang, Jean-Paul Ferrieux, Gérard Meunier, James Roudet, and Robert Périot
}

\begin{abstract}
This paper presents a design methodology dedicated to a two-winding transformer with large air gap and magnetic cores. To design this kind of components, it is necessary to consider the influence of inductive parameters on electrical magnitudes and the converter, which supplies this magnetic device. Indeed, this kind of a magnetic device has a large leakage inductance and a small magnetizing inductance. Therefore, to transfer the desired power, the transformer needs important reactive energy to magnetize magnetic core and to provide leakage flux. Like inductive parameters can be determined only when geometry is known, sizing has to be iterative. Moreover, resonant converters can be used to compensate inductive behavior, but modify electrical constraints of the transformer. A robust algorithm of design and all necessary tools are presented in order to make it easier to size such components. After the analytical design, 3-D FEM simulations and experimental measurements have been carried out in order to validate the theoretical study. Moreover, the power electronics converter has been optimized in order to improve the efficiency of power transfer. A prototype of $1.6 \mathrm{~kW} 100 \mathrm{kHz}$ with an air gap of $6 \mathrm{~mm}$ has been realized with its converter. The global efficiency is $93.3 \%$.
\end{abstract}

Index Terms - Contactless energy transfer, design methodology, inductively coupled power transfer (ICPT), resonant converter, virtual prototyping.

\section{INTRODUCTION}

M ANY studies deal with the design of a "transformer" without magnetic core and present algorithms of design [1]-[5]. However, only a few papers speak about the transformer with large air gap and magnetic core [6]. Some of them investigate the influence of geometrical and electrical parameters [7] or geometrical shapes [8] on energy transmission through large air gap of several centimeters. But they do not propose a complete design methodology. The presence of magnetic material improves the behavior of the transformer and limits the emission of magnetic field. This paper focuses on transmitting contactless power via large air gap transformers composed of two E cores and two windings (see Fig. 1), and where it is possible

The authors are with Grenoble Electrical Engineering laboratory, Saint Martin d'Heres 38402 Grenoble, France (e-mail: Jean-Romain.SIBUE@g2elab. grenoble-inp.fr; Gatien.KWIMANG@g2elab.grenoble-inp.fr; Jean-Paul. Ferrieux@g2elab.grenoble-inp.fr; Gerard.Meunier@g2elab.grenoble-inp.fr; james.roudet@g2elab.grenoble-inp.fr; robert.periot@transport.alstom.com).

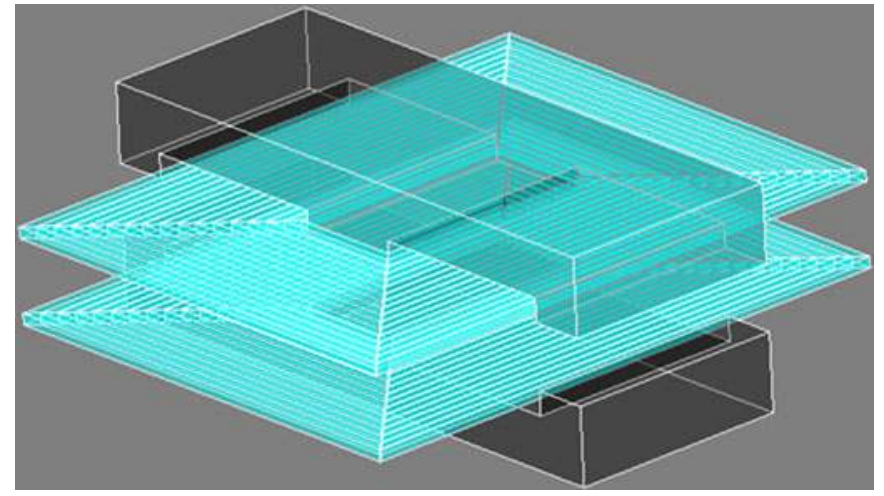

Fig. 1. 3-D view of a large air gap transformer with two windings.

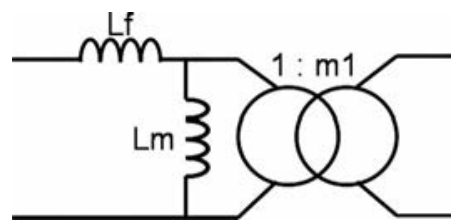

Fig. 2. Electrical equivalent scheme of a two-winding transformer with two inductances.

to align the primary and secondary magnetic circuits. A twowinding transformer with large air gap can be represented by an equivalent electrical scheme composed of two inductances and an ideal transformer (see Fig. 2). $L f$ and $L m$ represent, respectively, global leakage and magnetizing inductances, and $m 1$ is the transformer ratio. The presence of a large air gap leads to a greatly inductive behavior of the component. Indeed, the equivalent electrical model (see Fig. 2) is composed of a small magnetizing inductance $(L m)$ and a large leakage inductance $(L f)$. If this kind of transformer is supplied by a traditional full bridge, the primary current increases because of a large magnetizing current. Furthermore, the leakage inductance imposes an important voltage drop. In order to compensate reactive power, resonant converters are used to supply this kind of magnetic component [1]. Therefore, the design of a large air gap transformer and the design of the converter, which supplies this magnetic device are interdependent. Moreover, like inductive parameters can be determined only when geometry is known, the design algorithm has to be iterative.

Assumption of this design is based on the classical sizing of a high-frequency transformer. First, an inductive model is presented in order to determine the electrical equivalent scheme from geometry. Then, techniques of compensation of inductive 


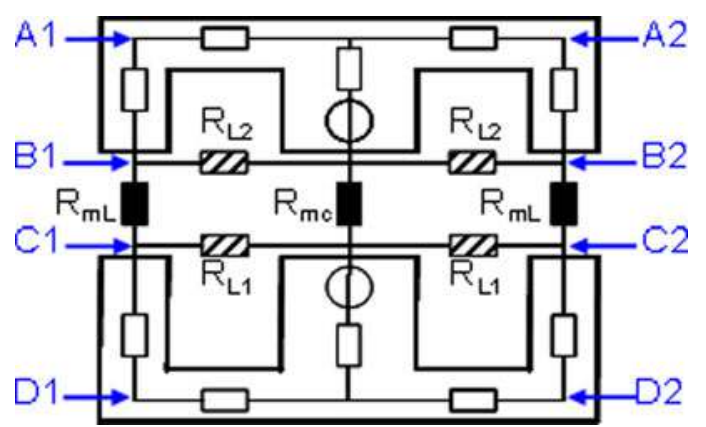

Fig. 3. Front view of a large air gap transformer with a reluctance network.

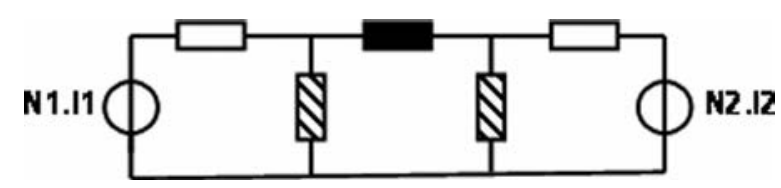

Fig. 4. Equivalent reluctance network.

behavior are briefly explained. Afterward, a general design algorithm is described. Then, from these tools, a prototype of $1.6 \mathrm{~kW} 100 \mathrm{kHz}$ with an air gap of $6 \mathrm{~mm}$ is designed and realized. Next, from geometrical specifications of the transformer, an estimation of losses is performed with the help FEM simulation. Finally, technological optimization of the converter and experimental results are presented.

\section{INDUCTIVE MODEL}

To realize the design, we suppose that induction in magnetic core and current densities in conductors are uniformed, magnetic material does not saturate, and flux is independent of the coils' location. The magnetic model is static. From this, we deduce electrical parameters to put them in an electrical model. Then, by placing this equivalent scheme in an electrical scheme of a converter, it is possible to determine electrical magnitudes required to the design.

An analytic model is calculated from a reluctance network. Thanks to the star-triangle Kennelly transformation, it is easy to deduce from the reluctance network (see Fig. 3) to the electrical scheme in T form (see Fig. 6).

In Fig. 3, a reluctance network is superimposed on the geometry of the E-shaped transformer. White, black, and hatched reluctances represent, respectively, magnetic cores, air gap, and leakage reluctances. This cutting was chosen because it emphasizes main physical phenomena, i.e., leakage flux and fringing effect near air gap. The model is based on the 2-D reluctance network of Fig. 3 where each individual reluctance $\left(R_{m c}, R_{\mathrm{mL}}, R_{L 1}\right.$, and $\left.R_{L 2}\right)$ takes into account 2-D and 3-D magnetic phenomena. The reluctances of magnetic cores are calculated from general (1) where $L$ and $S$ represent, respectively, the length of the mean distance of field's lines and the section gone across by flux

$$
R=\frac{1}{\mu_{r} \cdot \mu_{0}} \cdot \frac{L}{S}\left(H^{-1}\right) .
$$

The reluctances placed in the air gap can be decomposed into leakage reluctance and air gap reluctance. The first are calculated (a)

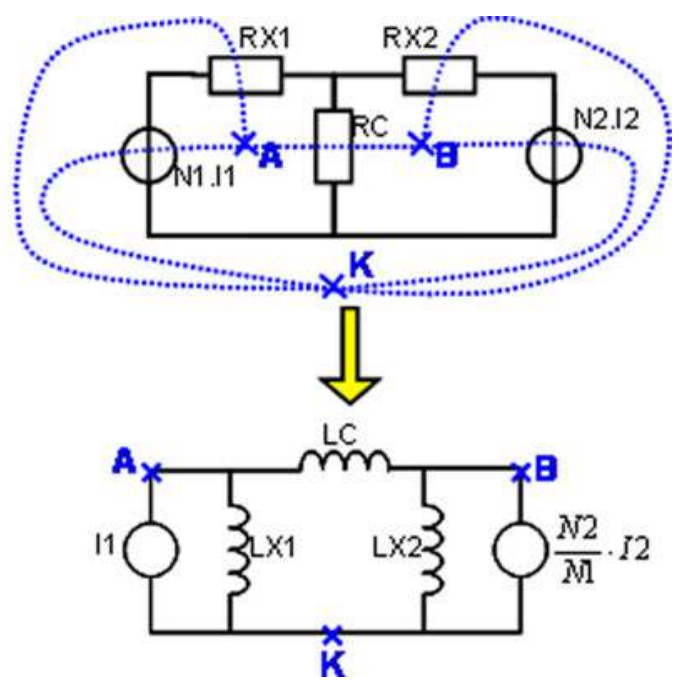

Fig. 5. Transit from equivalent the reluctance scheme to inductive equivalent scheme. (a) Reluctance scheme. (b) Inductive scheme.

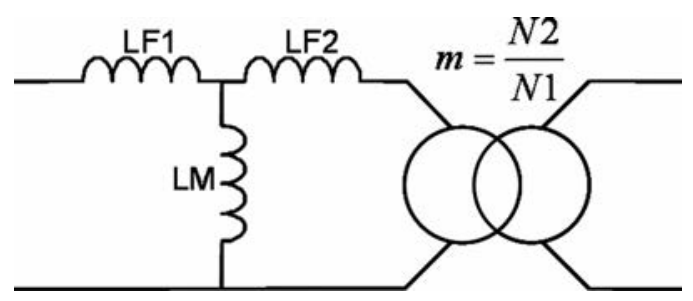

Fig. 6. Electrical equivalent scheme of a two-winding transformer with three inductances.

from the Ampere law [10]. The second are more complicated to estimate because it is necessary to consider the fringing effect. Different methods can be used to describe this phenomenon: the Schwarz-Christoffel transformation or the integral calculus of permeance (inverse of the reluctance) from flux path (supposed known) [9]-[13]. The expressions of reluctances $R_{m c}$ (11), $R_{\mathrm{mL}}$ (15), $R_{L 1}$, and $R_{L 2}$ (19) are given in the the Appendix.

Fig. 3 shows the reluctance network implemented in the front view of the large air gap transformer.

Due to symmetry, the magnetomotive force at points A1 and A2 are supposed to be equal. This is the same for couple of points (B1, B2), (C1, C2), and (D1, D2). Therefore, the global reluctance network can be simplified to obtain the equivalent reluctance network of Fig. 4. From this scheme and due to the triangle-star Kennelly transformation, the equivalent reluctance scheme of Fig. 5(a) is obtained. From this equivalent reluctance network, the inductive scheme of Fig. 5(b) is obtained.

Due to a new transformation, the final equivalent scheme of Fig. 6 is obtained. The scheme of Fig. 6 is not very useful for an electrical study because of its T structure. From this inductive model, it is possible to find the strictly equivalent scheme of Fig. 2. Equations (2), (3) and (4) allow us to find values of parameters $L f, L m$, and $m 1$ from inductive magnitudes of Fig. 6

$$
\begin{aligned}
L f & =\left(1-k^{2}\right) \cdot(L F 1+L M) \\
L m & =k^{2} \cdot(L F 1+L M)
\end{aligned}
$$




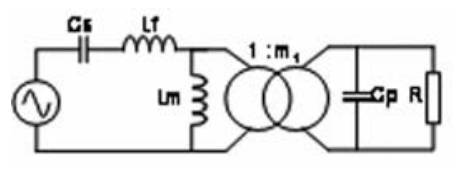

(a)

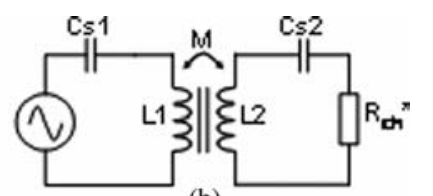

(b)
Fig. 7. Double resonance converter. (a) Series-parallel. (b) Series-series.

$$
m 1=\frac{1}{k_{2}} .
$$

These expressions depend on coupling coefficient $k$ (7) and $k_{2}(6)$, which are, respectively, global and secondary coupling coefficient. The distinction between primary $\left(k_{1}\right)(5)$ and secondary $\left(k_{2}\right)$ coupling coefficients is necessary when primary and secondary magnetic cores or windings are different. For example, when primary is longer than secondary or when primary winding window is higher than secondary winding window

$$
\begin{aligned}
k_{1} & =\frac{L M}{L M+L F 1} \\
k_{2} & =\frac{L M}{L M+L F 2} \\
k & =\sqrt{k_{1} \cdot k_{2}} .
\end{aligned}
$$

\section{COMPENSATION OF INDUCTIVE BEHAVIOR AND REACTIVE ENERGY}

The mode of compensation (series or parallel) depends on what kind of converter is used [1]. In this study, we are interested in dc-dc voltage conversion. Therefore, it is not possible to put a capacitor in parallel of the primary. In Fig. 7 , inverter and rectifier are, respectively, represented by an equivalent alternative voltage source and an equivalent resistor.

By placing a capacitor in series with the primary, we compensate the voltage drop across leakage inductance $L f$ with seriesparallel compensation (see Fig. 7(a)) and the primary inductance with series-series compensation (see Fig. 7(b)). The secondary capacitor can be in series or in parallel. Series-parallel and series-series, secondary capacitor compensates, respectively, magnetizing inductance and secondary inductance [1], [14].

Due to a generalized average model and a first harmonic complex approach, a model of these converters was found and used to adjust series and parallel resonant frequencies [14]-[17]. The primary resonant frequency has more effects on output characteristic than the secondary one. Therefore, to adjust these frequencies, the first step consists in determining the primary resonant frequency. The best output characteristic is obtained for a switching frequency slightly higher than the primary resonant frequency. Now, the primary resonant and the switching frequency are fixed, and the secondary resonant frequency can be used to maximize full bridge power factor ratio and/or minimize primary current [14].

\section{DESIGN Algorithm}

To design a large air gap transformer with magnetic cores, two materials are to be sized: copper and iron. It is not the volume of these two materials that is interesting, but their areas. Indeed, the copper and iron surfaces limit, respectively, current density and induction in order to maintain a good working temperature. $A c$ and $A i$ represent, respectively, the copper and iron areas. But $A c$ and $A i$ are interdependent. Therefore, a global design is necessary. From specifications and electrical magnitudes, it is possible to calculate the product of these two necessary areas, noted $A c A i$. Then, $A c$ and $A i$ are split so that their product is equal to $A c A i$. For low-power applications, the designer chooses a magnetic core that has an $A c A i$ product superior or equal to those calculated. Iron area is therefore imposed and number of turns (primary and secondary) can be calculated. But for highpower applications, magnetic core does not exist. Therefore, the designer has to impose the ratio between copper area and iron area by imposing the geometry of magnetic cores or by adjusting number of primary turns, for example. In this design methodology, we suppose that the geometry of magnetic cores is free and the number of primary turns is imposed.

The algorithm-aided design has been realized with MATLAB. It is based on classical technique of design of high-frequency transformers and considers magnetizing current and voltage drop. Their magnitudes depend on final inductive parameters (calculated from the 3-D analytic model due to a reluctance network), which can be estimated only when the geometrical characteristics of the magnetic component are known. Therefore, the design has to be iterative but it converges toward a unique solution. In summary, the iteration aims at transmitting the desired power with the specified constraints (number of turns, available area) by minimizing the primary current. The criterion of convergence consists in minimizing the absolute relative error of primary efficient current between two successive iterations.

Fig. 8 represents a simplified organization chart of the algorithm-aided design. User fills in specifications (see Fig. 9) and provides inductive parameters of the transformer, which he/she estimates appropriate in order to initialize the program. From these estimated values, electrical magnitudes are calculated and product areas are computed in order to initialize the design (see Fig. 8). For the same specifications and different initial parameters, we obtain a unique solution. This has an influence only on the time of calculation and the number of iterations. Therefore, the accuracy of these parameters is not important.

The first field "Specifications" in Fig. 9 corresponds to the classical specification of a converter and extra data about the large air gap. The field "Mechanical constraints" corresponds to geometrical constraints (available area). The field "Initial parameter of transformer" corresponds to initial inductance imposed by user. The field "Converter" corresponds to the choice of converter (series-series resonance converter or series-parallel) and the choice of control (constant duty cycle and variable frequency or variable duty cycle and constant frequency). The other parameters of this field allow us to limit the range of frequency and duty cycle during the adjustment of resonant frequencies (values of resonant capacitors). The more the parameters are low, the more the computation time is long because of computation step that they imposed, but they have no consequences on 


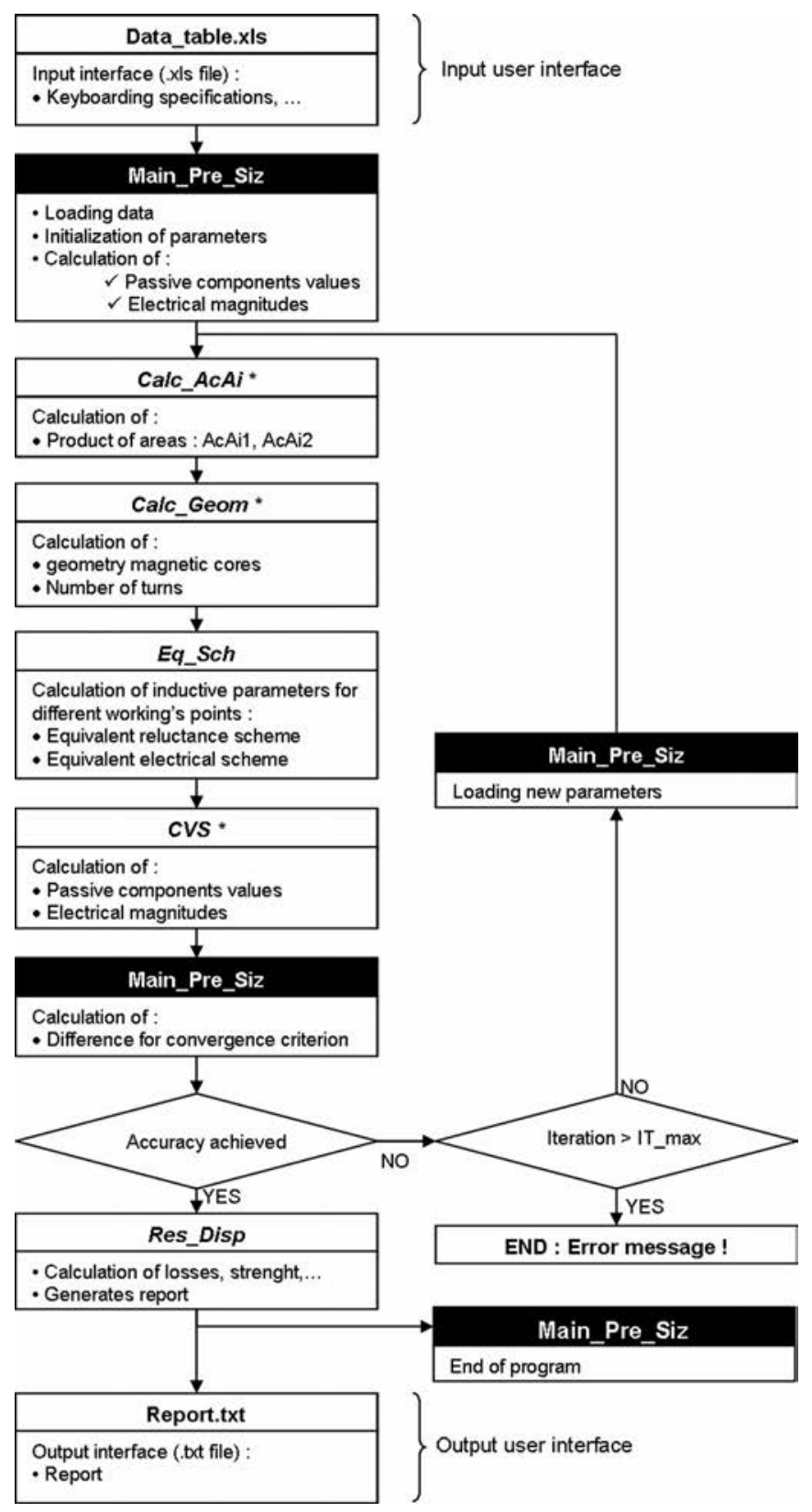

Fig. 8. Algorithm of designing of a large air gap transformer.

the solution. The fields "Design specifications" and "Conductor specifications" correspond to classical electrical constraints for the design of a magnetic component. The field "Algorithm parameters" corresponds to the parameters dedicated to this design methodology.

The function "Calc_AcAi" calculates suitable primary and secondary products of areas (AcAi1 and AcAi2). "Calc_Geom" determines geometries of magnetic cores. From AcAil and the number of primary turns (imposed by user), the program calculates the primary iron area (Ai1). From the figure in front of the "Mechanical constraints" in Fig. 9, we can deduce three expressions (8)-(10) with three unknowns: $p$ (the depth of magnetic cores), $n c$ (the width of the central leg of magnetic cores), and

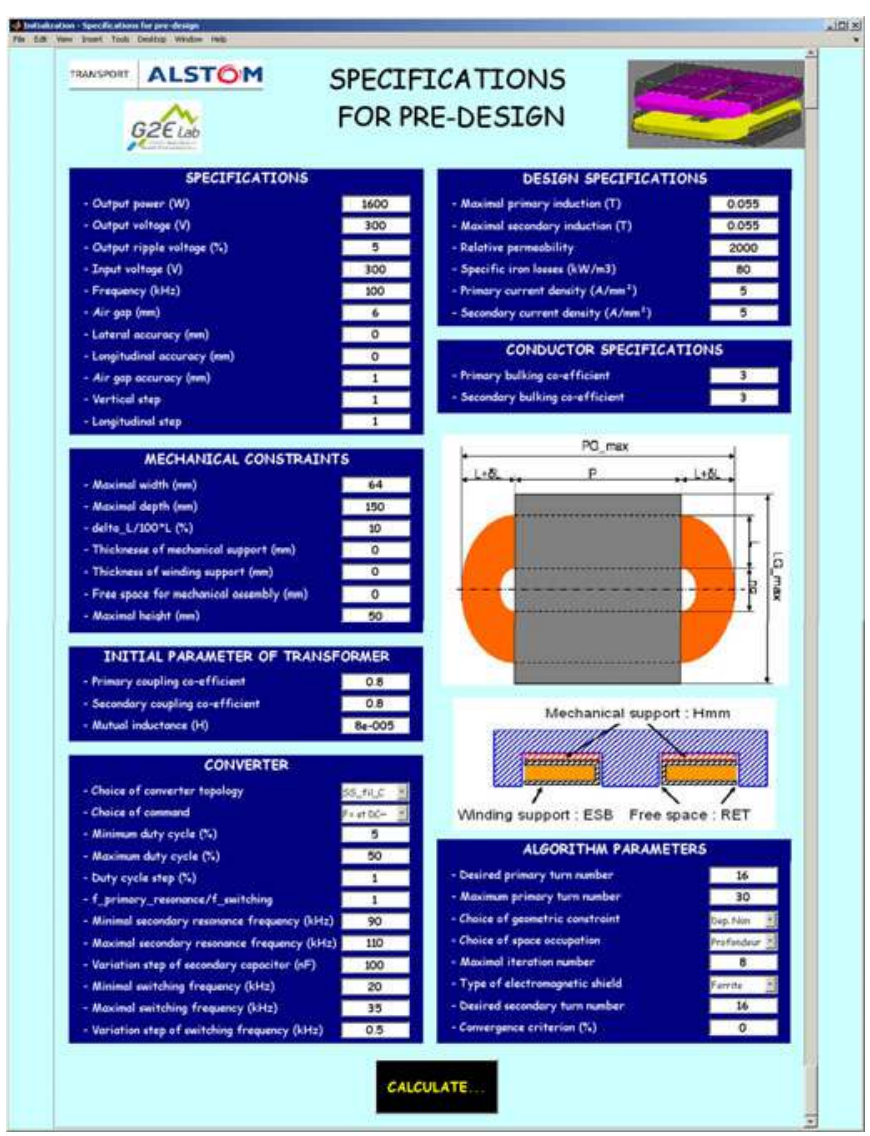

Fig. 9. Input interface of the predesigning tool.

$L$ (the width of winding windows)

$$
\begin{aligned}
A i 1 & =p \cdot n c \\
\text { PG_ } \max & =2 \cdot L \cdot(1+\delta L)+p \\
\text { LG__ } \max & =2 \cdot L+2 \cdot n c .
\end{aligned}
$$

Ai1, PG_max (the maximal depth of a magnetic component), LG_max (the maximal width of a magnetic component), and $\delta L$ (bulking coefficient of end of windings) are known or imposed by user. From these three equations, we can compute the geometry of magnetic cores that maximizes the occupation of available area (PG_max*LG_max). Finally, the number of secondary turns is adjusted so that the secondary iron area $(A i 2)$ be equal to primary iron area (Ai1). The heights of primary and secondary winding windows are adjusted to obtain primary and secondary necessary copper areas. "Eq_Sch" calculates the reluctance network and the equivalent electrical scheme. "CVS" adjusts resonant frequency and determines new value of the primary current. When the desired accuracy and the maximal number of iteration are not reached, new calculated inductive parameters become new initial parameters. When there is convergence, "Res_disp" displays the found solution. In summary, during an iteration, a new geometry of the magnetic component is determined from product areas. Then, new electrical magnitudes are computed. If there is no convergence, new product areas are computed from electrical magnitudes calculated 


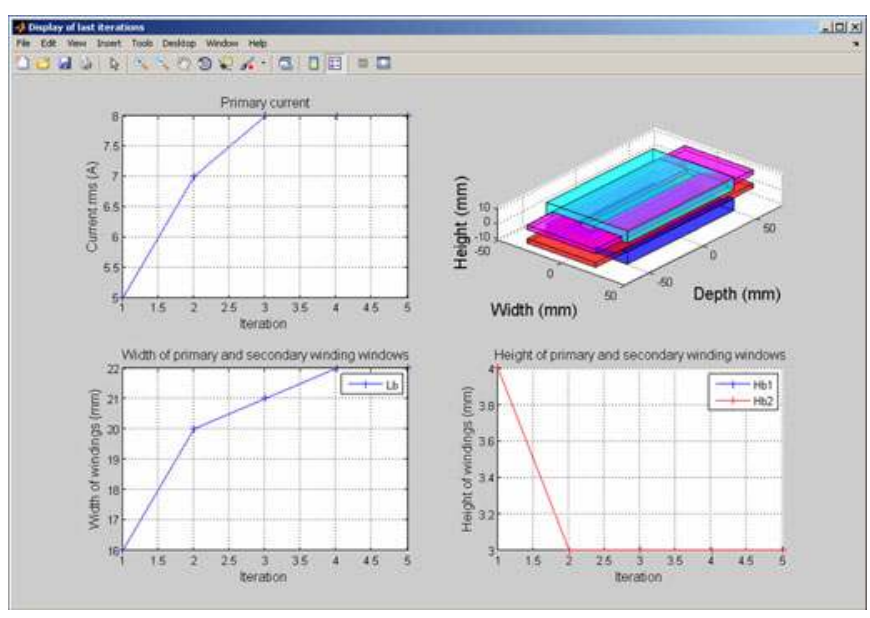

Fig. 10. Posttreatment interface.

TABLE I

MAIN SPECIFICATION

\begin{tabular}{|c|c|}
\hline \hline Designation & Value \\
\hline Air gap & $6 \mathrm{~mm}$ \\
\hline Ground covered area & $64 \mathrm{~mm} * 150 \mathrm{~mm}$ \\
\hline Switching frequency & $100 \mathrm{kHz}$ \\
\hline Input DC voltage & $300 \mathrm{~V}$ \\
\hline Output DC voltage & $300 \mathrm{~V}$ \\
\hline Output power & $1600 \mathrm{~W}$ \\
\hline Induction & $60 \mathrm{mT}$ \\
\hline Current density & $5 \mathrm{~A} / \mathrm{mm}^{2}$ \\
\hline
\end{tabular}

in the last iteration. This process is repeated until the desired accuracy is obtained.

To make it easier to interpret the results, a posttreatment interface has been realized (see Fig. 10) with the evolution of the primary current and sizes of winding windows versus iterations and a $3-D$ view of the final solution.

\section{Design of the Transformer and Resonant CONVERTER}

To design a $1.6 \mathrm{~kW}$ large air gap transformer, we resorted to the design tool introduced previously. This tool is adapted for high-power energy transfers and low-power ones. It needs to know the specifications of the transformer in terms of operating frequency, voltages, output power, etc. It also needs that the designer gives it the surface occupied by the magnetic circuit and the ends of windings: width and depth. In addition, it requires that the user enters the desired values of some constraints like current densities or inductions, both in the primary and the secondary of the transformer. Table I presents main specifications of this study. The chosen converter is the series-series resonant converter because it allows us to fairly share electrical constraints between the primary and the secondary of the magnetic component.

The geometry of the magnetic core is automatically calculated by the design tool. Therefore, the only degree of freedom is the number of turns of the windings. We impose that the number of turns of the primary winding is equal to the one of the secondary winding. The tool informed us that the transfer was possible for

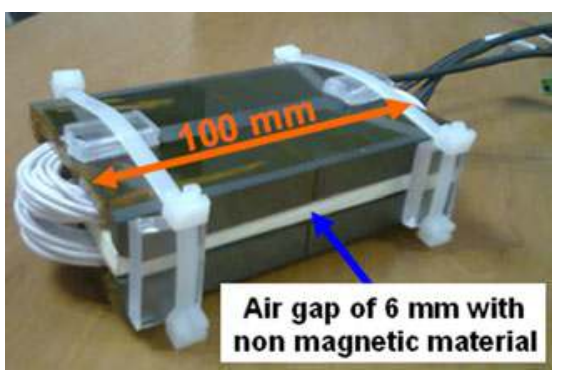

Fig. 11. Prototype of $1.6 \mathrm{~kW} 100 \mathrm{kHz}$.

TABLE II

Comparison BetweEn Results From the Design ToOl AND the Final PROTOTYPE

\begin{tabular}{|c|c|c|}
\hline \hline & Design tool & E 64/50/10 \\
\hline Width of central leg (in mm) & 11 & 10 \\
\hline Height of winding window (in mm) & 5 & 5 \\
\hline Depth of magnetic core (in mm) & 102 & 100 \\
\hline Width of winding window (in mm) & 21 & 22 \\
\hline \hline
\end{tabular}

TABLE III

COMPARISON OF INDUCTIVE PARAMETERS OF A MAGNETIC COMPONENT BETWEEN 3-D FEM SIMULATIONS AND EXPERIMENTAL RESULTS

\begin{tabular}{|c|c|c|c|}
\hline \hline & Ana. Model & 3D FEM & Exp. \\
\hline Magnetizing inductance M (in $\mu \mathrm{H})$ & 60 & 57 & 57 \\
\hline Primary inductance L1 (in $\mu \mathrm{H})$ & 76 & 75 & 80 \\
\hline Secondary inductance L2 (in $\mu \mathrm{H})$ & 76 & 75 & 78 \\
\hline \hline
\end{tabular}

a number of turns varying between 15 and 20 . We opted for 16 turns, a choice that allows using classical values of capacitors and Litz wire composed of 200 conductors of diameter $0.1 \mathrm{~mm}$.

The transformer prototype was built from existing planar E-shaped magnetic cores from the company Ferroxcube: E64/50/10 in ferrite 3C90 [18] (see Fig. 11). The primary and secondary magnetic circuits have been clamped to obtain a perfect alignment. Table II presents a comparison between results from the design tool and the final size of magnetic core geometry.

The design tool provides an inductive model of the magnetic component. These values were validated by simulations with the 3-D FEM software FLUX [19] and experimentally, as shown in Table III.

Experimental values are deduced from impedance measurements of Fig. 12 [20], [21]. Impedances are measured between $40 \mathrm{~Hz}$ and $10 \mathrm{MHz}$ with an Agilent $4294 \mathrm{~A}$ impedance analyzer. $Z \mathrm{oo}$ and $Z \mathrm{cc}$ represent, respectively, the open-circuit and short-circuit impedances. The lowest resonant frequency of the transformer is equal to $3 \mathrm{MHz}$, which is largely higher than the switching frequency $(100 \mathrm{kHz})$.

We obtained a theoretical value for resonant capacitors of $33.3 \mathrm{nF}$ for a $76 \mu \mathrm{H}$ inductance and a $100 \mathrm{kHz}$ switching frequency, which in practice corresponds to a $33 \mathrm{nF}$ capacitor, a common value. This is why we opted for 16 turns for both the primary and the secondary windings. 


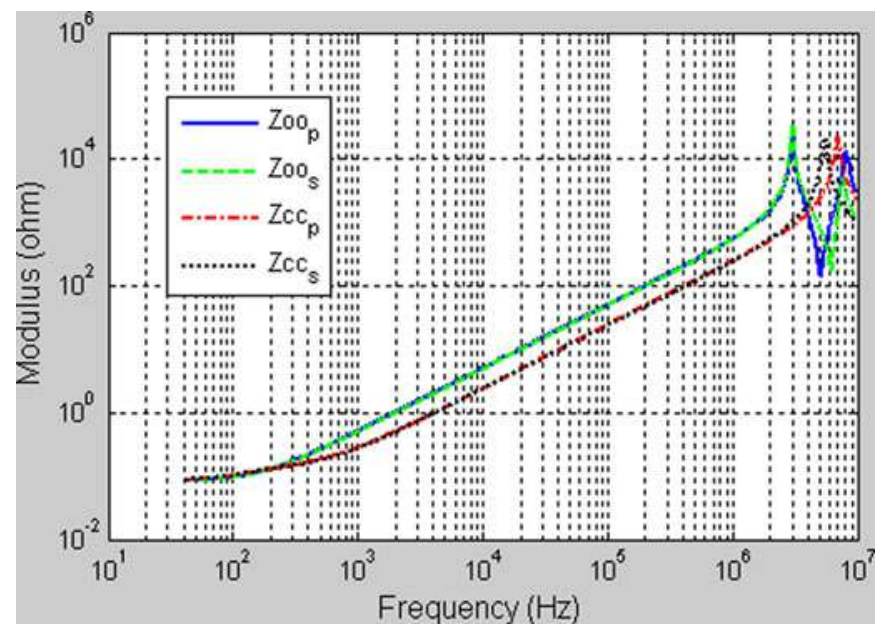

Fig. 12. Experimental measures of impedances of prototype.

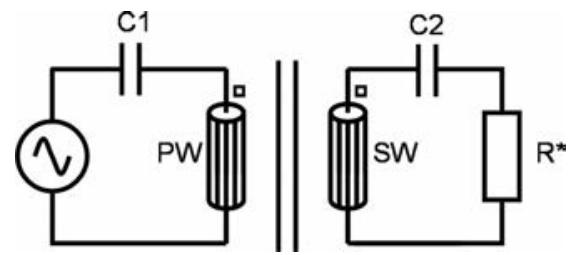

Fig. 13. Equivalent scheme of series-series resonant converter with a capacitive filter at the first harmonic.

\section{VIRTUAL PROTOTYPING}

To validate the theoretical design, computer aided design (CAD) or "virtual prototyping" was used. Indeed, a 3-D magnetic component has been simulated in working condition with an equivalent scheme of the converter due to numerical simulation with FLUX. In order to limit the computation time, we have considered only the equivalent scheme of the converter at the first harmonic at $100 \mathrm{kHz}$ of Fig. 13.

Another goal of the virtual prototyping is to be able to determine losses in windings (dc losses and proximity effect losses) and in magnetic core (with an equivalent complex permeability). Some papers deal with this problem [22]-[26]. Windings and magnetic cores properties are represented by a complex permeability. For windings, it is analytically calculated from [23] and [24]. And for magnetic material, it is computed from datasheet (specific power loss as a function of flux density with frequency as a parameter) [18].

Table IV presents losses in different parts of a magnetic component. Global losses are estimated to $14 \mathrm{~W}$ and its efficiency is of $99.2 \%$. Losses are estimated from integral computation of power densities on volume.

From electromagnetic simulation, it is possible to check that induction is conformed to the predicted results (see Fig. 14).

\section{TECHNOLOGICAL OPTIMIZATION OF THE CONVERTER}

The power converter is composed of a full bridge inverter, a large air gap transformer associated in series with resonant capacitors at its input and its output, a single-phase rectifier, and an ohmic resistance as load (see Fig. 15).
TABLE IV

LOSSES IN A MAGNETIC COMPONENT

\begin{tabular}{|c|c|}
\hline \hline Designation & Value \\
\hline Iron losses in primary magnetic core (in W) & 0.6 \\
\hline Iron losses in secondary magnetic core (in W) & 0.5 \\
\hline DC losses in primary winding (in W) & 5.1 \\
\hline Proximity effect losses in primary winding (in W) & 2.6 \\
\hline Global losses in primary winding (in W) & 7.7 \\
\hline DC losses in secondary winding (in W) & 3.2 \\
\hline Proximity effect losses in secondary winding (in W) & 2.0 \\
\hline Global losses in primary winding (in W) & 5.2 \\
\hline Global losses in magnetic component (in W) & 14 \\
\hline Efficiency of magnetic component (in \%) & 99.2 \\
\hline
\end{tabular}

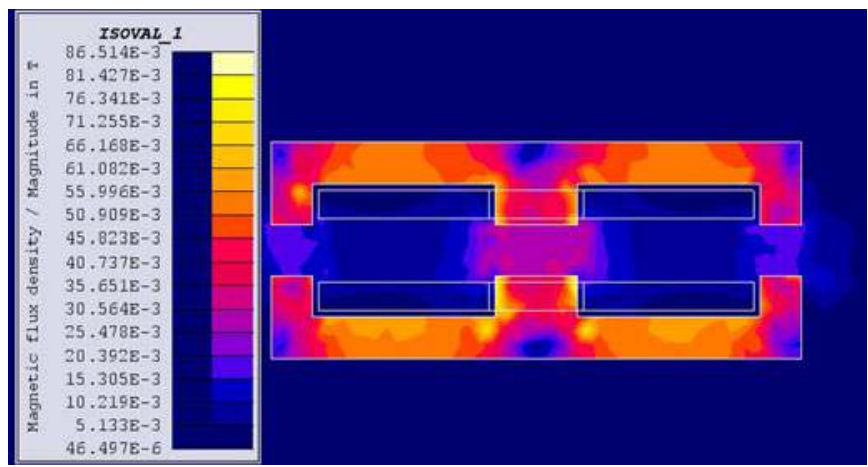

Fig. 14. 2-D view of induction for prototype of $1.6 \mathrm{~kW} 100 \mathrm{kHz}$.

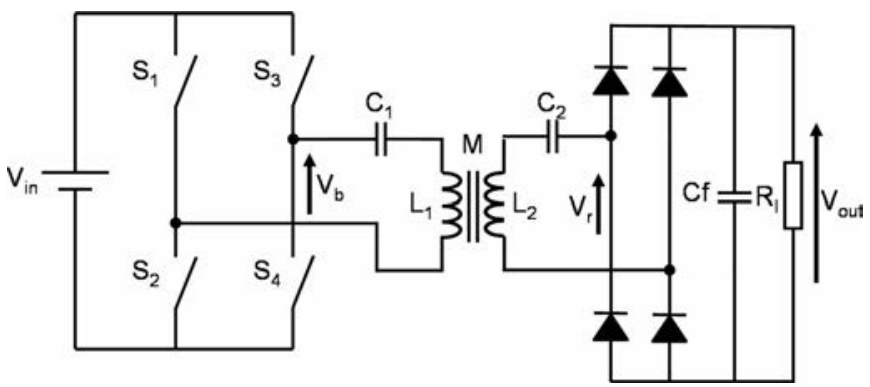

Fig. 15. Series-series resonant converter.

For our application, we used a phase-shifted controlled bridge. It is a structure widely used, and especially when the misalignment of secondary magnetic circuit with respect to the primary one is not a concern. This mode of control allows us to adjust the amplitude of the fundamental of the bridge voltage at a fixed frequency, and thus to adapt the level of output voltage or transmitted power. At the resonance, the phase shift of the firing signals for the two bridge legs results in an opposite behavior of these two legs. One will operate in a zero-current switching (ZCS) mode whereas the other one will operate in a zero-voltage switching (ZVS) mode. In this study, the leg composed of switches $\mathrm{S} 1 / \mathrm{S} 2$ will operate in the ZCS mode while the other one (S3/S4) will operate in the ZVS mode, as depicted in Fig. 16.

The designer will have to consider these differences at the time of choosing a technology of switches. Usually we could use either MOSFETs or insulated gate bipolar transistors (IGBTs) with a freewheeling diode in antiparallel. 


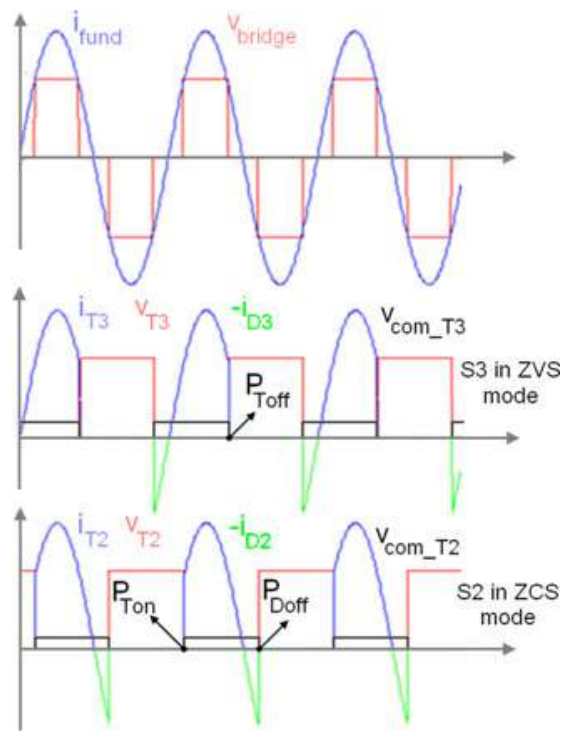

Fig. 16. Waveforms of S2 and S3 switches.

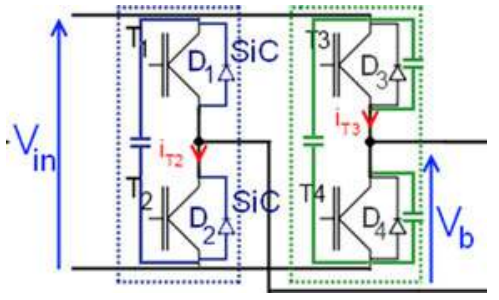

Fig. 17. Optimization of the full bridge.

In the ZCS mode, the critical losses are the turn-on losses due to recovery diode. For this reason, IGBTs with antiparallel fast Si recovery time diodes are preferred to MOSFETs handicapped by their body diodes. A better efficiency can be expected if we use IGBTs with Schottky SiC diodes instead of fast recovery time Si diode. That is what we could observe when we compared the gain obtained with a fast recovery time Si diode and those with a SiC Schottky. The replacement of integrated Si diode by a fast Si diode leads to a $2.6 \mathrm{~W}$ loss reduction on the ZCS leg, whereas the use of a Schottky SiC diode causes a $16.8 \mathrm{~W}$ loss reduction, and thus it is about seven times more efficient than the fast Si diode. Hence, we used Schottky Sic diodes for the ZCS leg.

In the ZVS mode, the critical losses are the turn-off switching losses in the transistor. Fast Si diodes in antiparallel are not required any longer, because they switch at zero current, and hence both IGBTs and MOSFETs are suitable candidates. However, we decided to use IGBTs for this leg, after comparing the performances of IGBTs and MOSFETs with low recovery time diodes. In order to limit the turn-off losses, we planned to add snubber capacitors in parallel of each IGBT of the ZVS leg, as shown in Fig. 17.

As we can see in Fig. 18, the losses are half-concentrated in the full bridge. Other sources of losses consist in the transformer and the bridge rectifier. For transferring $1.6 \mathrm{~kW}$, the prototype needs a theoretical input power of $1696 \mathrm{~W}$, which corresponds

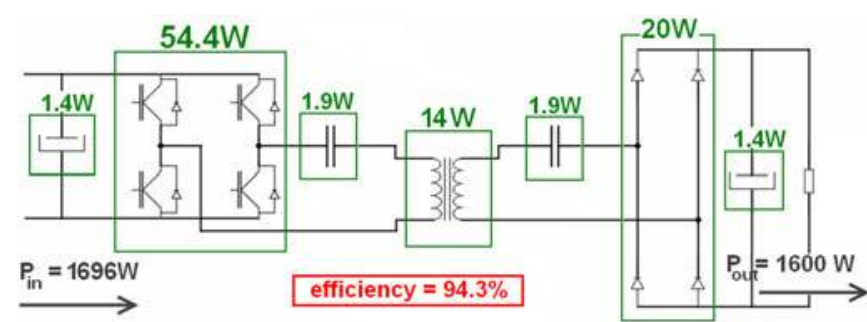

Fig. 18. Losses balance.

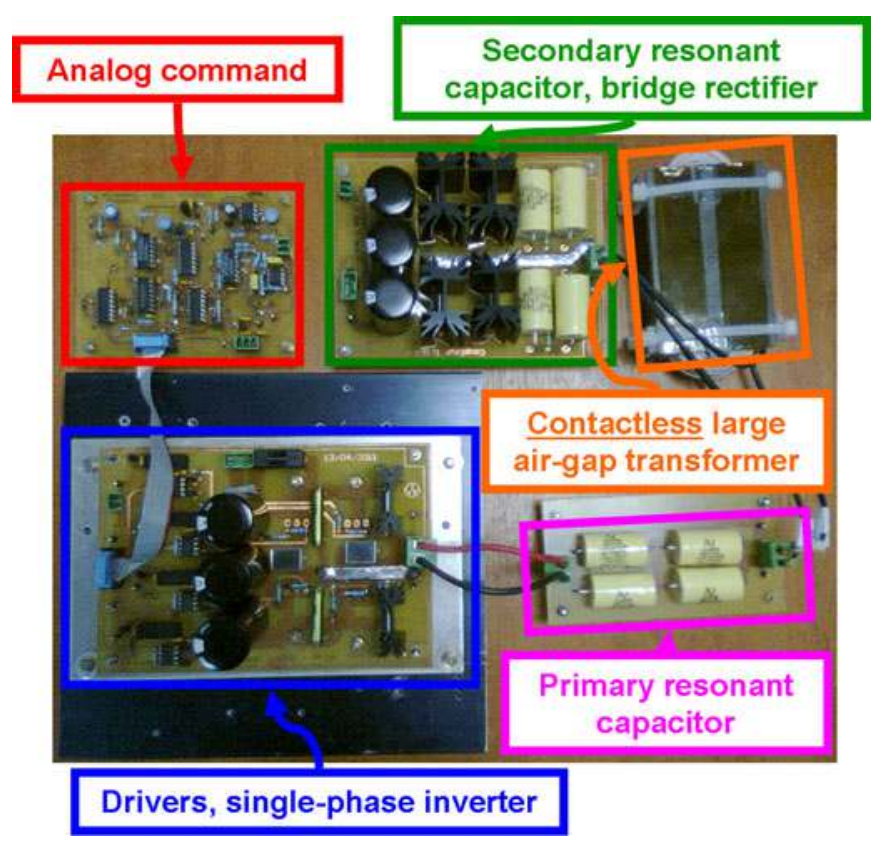

Fig. 19. $1.6 \mathrm{~kW}$ prototype.

to a theoretical efficiency of $94.3 \%$, value in agreement with what can be seen in the literature.

\section{EXPERIMENTAL RESULTS}

We carried out an experiment on the $1.6 \mathrm{~kW}$ prototype. It consists of the transformer built according to the design established in the Section V, and integrated into the series-series resonant converter of Section VII. The transformer thus realized is light, $578 \mathrm{~g}$. Its mass and size are in the same range as those of the rotating transformer used to transfer $1 \mathrm{~kW}$ power over a $2 \mathrm{~mm}$ air gap [6]. The presence of the small air gap and the shape of magnetic core allow minimizing the apparent power of the large air gap transformer and therefore the size compare to prototypes of [7] and [18]. But it needs a system that is able to align the secondary compared with primary. The full bridge operates at a frequency of $100 \mathrm{kHz}$ and is powered by a $300 \mathrm{~V}_{\mathrm{dc}}$ voltage source. The output voltage is controlled to a level of $300 \mathrm{~V}_{\mathrm{dc}}$ by a PI controller. Fig. 19 presents the complete prototype. Contactless power transfer is carried out by the designed transformer. The feedback loop is realized with wires but it can be replaced by an antenna or two additional windings in the transformer which work at a higher frequency than the switching frequency, 
(a)

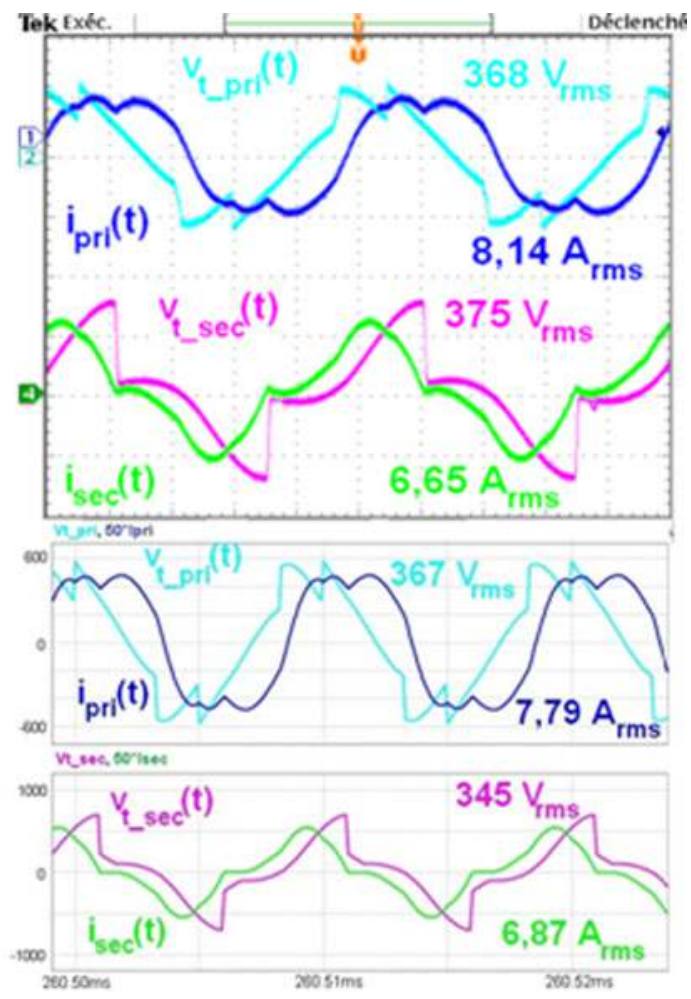

Fig. 20. Input and output current and voltage of a large air gap transformer. (a) Experimental results. (b) Simulation software: PSIM.

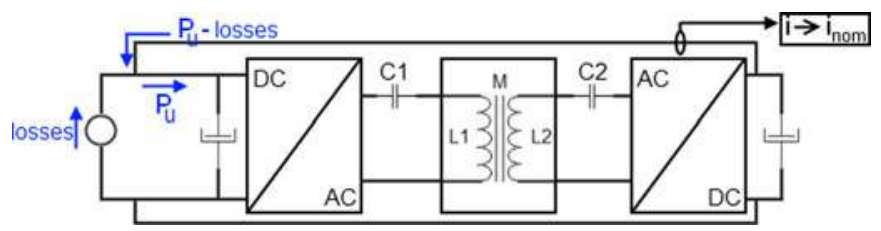

Fig. 21. Principle of the opposition method.

in order to obtain a complete contactless system (power and signal) [27].

The $1.6 \mathrm{~kW}$ contactless power transfer was successful. The results obtained are in good agreement with the simulation as shown in the Fig. 20. In this figure, we compared the waveforms of currents and voltages at the terminals of the transformer obtained with the electrical simulation software PSIM and those observed experimentally. Both of them fit quite well and show that the choices and hypotheses made during the phase of designing the converter were relevant.

Then, we planned to perform various tests in a close loop: variation of the load resistance, variation of the value of the source voltage, and variation of the output voltage set value. For each of these cases, the prototype managed to transfer the desired amount of power to the load, as expected.

In order to determine precisely the global losses, we resorted to "opposition method." In this approach, the output current does not flow into the load anymore, but is carried toward the input of the inverter by a feedback loop. In this way, the voltage source only provides a level of power equal to the losses that occur in the converter, as described in Fig. 21. The use of this method

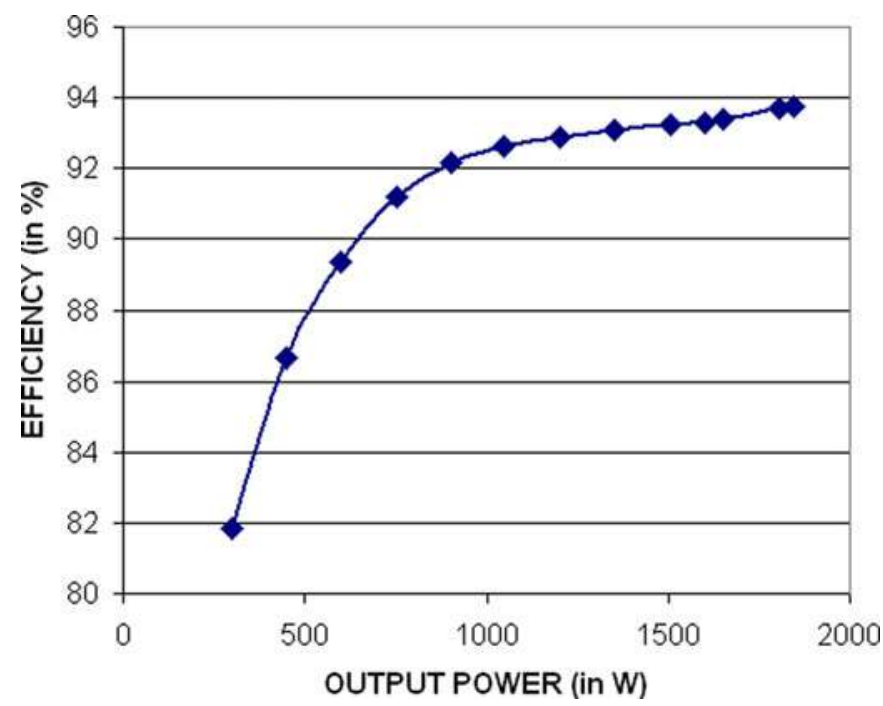

Fig. 22. Evolution of the efficiency.

supposes that the voltage levels of the input and the output have to be the same, and requires a regulation of the output current.

To set the output current to its rated value, we decided to reuse the PI controller of the analog command, but with a modification of its parameters' values to take into account the new dynamics of the system when the load was removed. For the rated value of the output current, measurements give $1599 \mathrm{~W}$ for the output power and $104.9 \mathrm{~W}$ for the total losses, thus an efficiency of $93.3 \%$. The theoretical efficiency was estimated to $94.3 \%$. The difference is of $1 \%$. It can be explained by the fact that losses in the capacitors and the transformer are calculated at the first harmonic. Owing to an "opposition method," we can evaluate with accuracy, efficiency versus a large output power variation. When duty cycle is maximal, the maximum output power is equal to $1848 \mathrm{~W}$ and the efficiency is around 93.8\%. Fig. 22 presents the efficiency as a function of output power from $298 \mathrm{~W}$ (1 A) to $1848 \mathrm{~W}$ (6.1 A).

\section{CONCLUSION}

This paper presents a design methodology to size a transformer with large air gap and magnetic cores. The electrical model of a magnetic device and the converter model necessary to design are presented. In spite of simplicity of a reluctance network and hypotheses necessary for implementation of this method, it is possible to achieve a sufficient accuracy to a step of predesign. It is not a generic inductive model. The step in the calculation of a model can be replaced by 3-D finite element method simulation in order to deduce inductive parameters. By using the described method, it is possible to design very quickly a large air gap transformer with a good accuracy. From the design tool, a prototype of $1.6 \mathrm{~kW} 100 \mathrm{kHz}$, an air gap of $6 \mathrm{~mm}$ has been realized with its converter. In order to improve the global efficiency, full bridge has been optimized by considering different ways of switching (ZVS and ZCS). The maximum efficiency is equal to $93.8 \%$ and was reached for an output power of $1848 \mathrm{~W}$. The comparison between theoretical and experimental results 
TABLE V

GEOMETRIC PARAMETER OF A MAGNETIC COMPONENT

\begin{tabular}{|c|c|}
\hline \hline Parameter & Description \\
\hline $\mathrm{h}$ & Height of winding window \\
\hline $\mathrm{h}_{\mathrm{b}}$ & Height of winding support \\
\hline $\mathrm{w}_{\mathrm{w}}$ & Width of winding window \\
\hline $\mathrm{w}_{\mathrm{c}}$ & Width of central leg of magnetic core \\
\hline $\mathrm{w}_{\mathrm{l}}$ & Width of lateral leg of magnetic core \\
\hline $\mathrm{w}_{\mathrm{j}}$ & $\begin{array}{c}\text { Width of junction between lateral and central legs } \\
\text { of magnetic core }\end{array}$ \\
\hline $\mathrm{d}$ & Depth of magnetic core \\
\hline $\mathrm{g}$ & Air gap \\
\hline$\mu_{\mathrm{r}}$ & Relative permeability \\
\hline
\end{tabular}

for inductive and electrical magnitudes shows that the reached accuracy is good and validates the general method of design and different tools presented in this paper. Future works will take into account the misalignment between the primary and the secondary. An optimization of the power electronic converter and the contactless energy system (transformer) will be performed in order to transfer the desired power for all positions included in the specifications.

\section{APPENDIX}

Table $\mathrm{V}$ presents the geometric parameter of a magnetic component necessary to calculate reluctances.

\section{A. Expression of Magnetizing Reluctance of the Central Leg: $R_{m c}$}

$$
\begin{aligned}
P_{m c 1} & =\mu_{0} \cdot\left(\frac{w_{c} \cdot d}{g}+\frac{2}{\pi} \cdot \ln \left(1+\frac{\pi \cdot h}{g}\right) \cdot d\right) \\
P_{m c 2} & =\mu_{0} \cdot\left(\frac{4}{\pi} \cdot \ln \left(1+\frac{\pi \cdot h}{2 \cdot(h+g)}\right) \cdot d\right) \\
P_{m c 3} & =\mu_{0} \cdot\left(\frac{2}{\pi} \cdot \ln \left(1+\frac{\pi \cdot h}{g}\right) \cdot w_{c}\right) \\
R_{m c} & =\frac{10^{3}}{P_{m c 1}+P_{m c 2}+P_{m c 3}} .
\end{aligned}
$$

\section{B. Expression of Magnetizing Reluctance of the} Lateral Legs: $R_{\mathrm{mL}}$

$$
\begin{aligned}
P_{m L 1}= & \mu_{0} \cdot\left(\frac{w_{l} \cdot d}{g}+\frac{1}{\pi} \cdot \ln \left(1+\frac{\pi \cdot h}{g}\right) \cdot d\right) \\
P_{m L 2}= & \frac{\mu_{0} \cdot d}{\pi} \cdot\left(\ln \left(1+\frac{\pi \cdot\left(h+w_{l}\right)}{g}\right)\right. \\
& \left.+2 \cdot \ln \left(1+\frac{\pi \cdot h}{2 \cdot(g+h)}\right)\right) \\
P_{m L 3}= & \mu_{0} \cdot\left(\frac{2}{\pi} \cdot \ln \left(1+\frac{\pi \cdot h}{g}\right) \cdot w_{l}\right) \\
R_{\mathrm{mL}}= & \frac{10^{3}}{P_{m L 1}+P_{m L 2}+P_{m L 3}} .
\end{aligned}
$$

C. Expression of Leakage Reluctances: $R_{L 1}$ and $R_{L 2}$

$$
\begin{aligned}
P_{L \_2 \mathrm{D}} & =\frac{\mu_{0} \cdot d \cdot\left(h-2 \cdot h_{b}\right)}{3 \cdot w_{w}}+\frac{\mu_{0} \cdot d \cdot\left(2 \cdot h_{b}+g / 2\right)}{w_{w}} \\
P_{L \_3 \mathrm{D} 1} & =\frac{2 \cdot \mu_{0} \cdot\left(h-2 \cdot h_{b}\right)}{3 \cdot \pi} \cdot \ln \left(1+\frac{\pi \cdot w_{l}}{w_{w}}\right) \\
P_{L \_3 \mathrm{D} 2} & =\frac{2 \cdot \mu_{0} \cdot\left(2 \cdot h_{b}\right)}{\pi} \cdot \ln \left(1+\frac{\pi \cdot w_{l}}{w_{w}}\right)+\frac{1 \cdot \mu_{0} \cdot \pi \cdot w_{x}}{4} \\
R_{L 1} & =R_{L 2}=\frac{10^{3}}{P_{L \_2 \mathrm{D}}+P_{L \_3 \mathrm{D} 1}+P_{L \_3 \mathrm{D} 2}} .
\end{aligned}
$$

\section{REFERENCES}

[1] J. Sallan, J. L. Villa, A. Llombart, and J. F. Sanz, "Optimal design of ICPT systems applied to electric vehicle battery charge," IEEE Trans. Ind. Electron., vol. 56, no. 6, pp. 2140-2149, Jun. 2009.

[2] P. Meyer, P. Germano, M. Markovic, and Y. Perriard, "Design of a contactless enrgy transfer system for desktop peripherals," IEEE Trans. Ind. Appl., vol. 47, no. 4, pp. 1643-1651, Jul./Aug. 2011.

[3] X. Liu and S. Y. Hui, "Optimal design of a hybrid winding structure for planar contactless battery charging platform," IEEE Trans. Power Electron., vol. 23, no. 1, pp. 455-463, Jan. 2008

[4] T. Bieler, M. Perrottet, V. Nguyen, and Y. Perriard, "Contactless power and information transmission," IEEE Trans. Ind. Appl., vol. 38, no. 5, pp. 1266-1272, Sep./Oct. 2002.

[5] J. de Boeij, E. Lomonova, and J. Duarte, "Contactless planar actuator with manipulator: a motion system without cables and physical contact between the mover and the fixed world," IEEE Trans. Ind. Appl., vol. 45, no. 6, pp. 1930-1938, Nov./Dec. 2009.

[6] K. D. Papastergiou and D. E. Macpherson, "An airbone radar power supply with contactless transfer of energy - Part I: Rotating transformer," IEEE Trans. Ind. Electron., vol. 54, no. 5, pp. 2874-2884, Oct. 2007.

[7] R. Mecke and C. Rathge, "High frequency resonant inverter for contact less energy transmission over large air gap," in Proc. IEEE 35th Annu. Power Electron. Spec. Conf., Jun. 2004, vol. 3, pp. 1737-1743.

[8] M. Chigira, Y. Nagatsuka, Y. Kaneko, S. Abe, T. Yasuda, and A. Suzuki, "Small-size light-weight transformer with new core structure for contactless electric vehicle power transfer system," in Proc. IEEE Energy Conv. Cong., 2011, pp. 260-266.

[9] A. Balakrishnan, W. T. Joines, and T. G. Wilson, "Air-gap relucatnce and inductance calculations for magnetic circuits using a Schwarz-Christoffel transformation," IEEE Trans. Power Electron., vol. 12, no. 4, pp. 654-662, Jul. 1997.

[10] G. A. Cividjian, "Permeance of Fringing Flux," IEEE Trans. Magn., vol. 45, no. 2, pp. 694-700, Feb. 2009

[11] J. Cale, S. D. Sudhoff, and L. Q. Tan, "Accurately modeling EI core inductors using a high-fidelity magnetic equivalent circuit approach," IEEE Trans. Magn., vol. 42, no. 1, pp. 40-46, Jan. 2006.

[12] M. A. Batdorff and J. H. Lumkes, "High -fidelity magnetic equivalent circuit model for an axisymmetric electromagnetic actuator," IEEE Trans. Magn., vol. 45, no. 8, pp. 3064-3072, Aug. 2009.

[13] W. Zhang, Q. Chen, S. C. Wong, C. K. Tse, and X. Ruan, "A novel transformer for contactless energy transmission systems," in Proc. IEEE Energy Conver. Congr. Expo., 2009, vol. 1-6, pp. 2679-2685.

[14] J.-R. Sibué, J.-P. Ferrieux, G. Meunier, and R. Périot, "Convertisseurs à double résonance pour l'alimentation de transformateur faiblement couplé," Électron. Puissance Futur, Jul. 2010.

[15] J. A. Martin-Ramos, J. Diaz, A. M. Pernia, J. M. Lopera, and F. Nuno, "Dynamic and steady-state models for the PRC-LCC resonant topology with a capacitor as output filter," IEEE Trans. Ind. Electron., vol. 54, no. 4, pp. 2262-2275, Aug. 2007.

[16] J. H. Cheng and A. F. Witulski, "Analytic solutions for LLCC parallel resonant converter simplify use of two and three element converters," IEEE Trans. Power Electron., vol. 13, no. 2, pp. 235-243, Mar. 1998.

[17] C. H. Tang, Y. Sun, Y. G. Su, S. K. Nguang, and A. P. Hu, "Determining multiple steady-state ZCS operating points of a switch mode contactless 
power transfer system," IEEE Trans. Power Electron., vol. 24, no. 2, pp. 416-425, Feb. 2009.

[18] Soft Ferrites and accessories_Data Handbook, Ferroxcube, Eindhoven, Netherlands, Sep. 2008.

[19] Cedrat. Flux ${ }^{\circledR}$, [Online]. Available: www.cedrat.com

[20] B. Cogitore, J. P. Keradec, and J. Barbaroux, "The two-winding transformer: an experimental method to obtain a wide frequency range equivalent circuit," IEEE Trans. Instum. Meas., vol. 43, no. 2, pp. 364-371, Apr. 1994.

[21] A. Schellmans, P. Fouassier, J. P. Keradec, and J. L. Schanen, "Equivalent circuits for transformers based on one-dimensional propagation : accounting for multilayer structure of windings and ferrite losses," IEEE Trans. Magn., vol. 36, no. 5, pp. 3778-3784, Sep. 2000.

[22] G. Meunier, V. Charmoille, C. Guerin, P. Labie, and Y. Marechal, "Homogenization for periodical electromagnetic structure : which formulation?," IEEE Trans. Magn., vol. 46, no. 8, pp. 3409-3412, Aug. 2010.

[23] E. Matagne, "Macroscopic electric characterization of bundles of conductors," IEEE Trans. Magn., vol. 31, no. 3, pp. 1464-1467, May 1995.

[24] E. Matagne, "Modélisation magnétique macroscopique des faisceaux de conducteurs," J. Phys. III, no. 3, pp. 509-517, Mar. 1993.

[25] C. F. Foo, D. M. Zhang, and H. Saotome, "Calculation of iron losses in ferrite toroids using FEM and complex vectors," IEEE Trans. Magn., vol. 35, no. 5, pp. 3451-3453, Sep. 1999.

[26] H. Saotome and Y. Sakaki, "Iron loss analysis of Mn-Zn ferrite cores," IEEE Trans. Magn., vol. 33, no. 1, pp. 728-734, Jan. 1997.

[27] T. Bieler, M. Perrottet, V. Nguyen, and Y. Perriard, "Contactless power and information transmission," IEEE Trans. Ind. Appl., vol. 38, no. 5, pp. 1266-1272, Sep.-Oct. 2002.

[28] H. Matsumoto, Y. Neba, K. Ishizaka, and R. Itoh, "Comparison of characteristics on planar contactless power transfer systems," IEEE Trans. Power Electron., vol. 27, no. 6, pp. 2980-2993, Jun. 2012. 